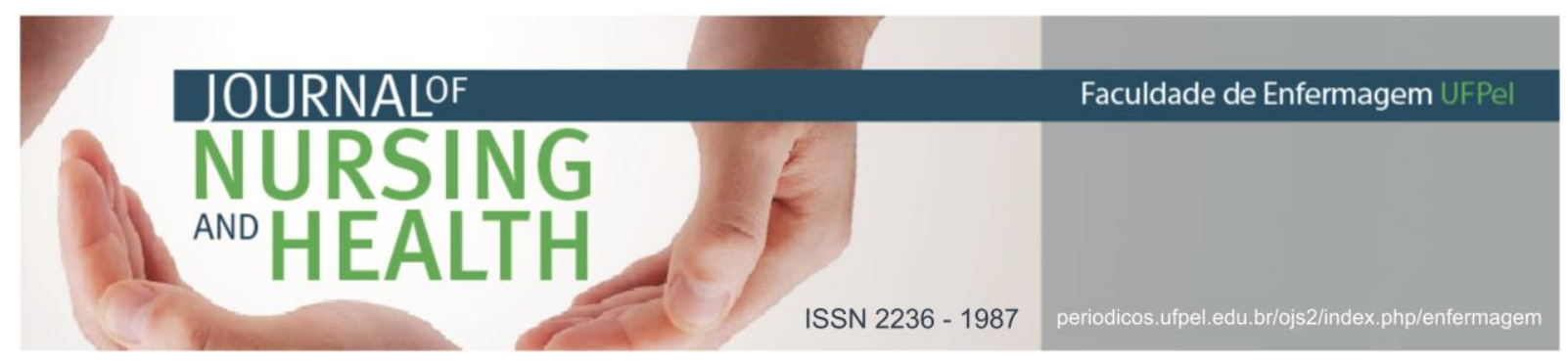

ARTIGO ORIGINAL

\title{
Ouvidores de vozes: características e relações com as vozes
}

\author{
Voice listeners: characteristics and relationship with the voices
}

Oidores de voces: características y relaciones con las voces

Kantorski, Luciane Prado; Machado, Roberta Antunes²; Alves, Poliana Farias³; Pinheiro, Guilherme Emanuel Weiss ${ }^{4}$; Borges, Luana Ribeiro ${ }^{5}$

Como citar este artigo: Kantorski LP, Machado RA, Alves PF, Pinheiro GEW, Borges LR. Ouvidores de vozes: características e relações com as vozes. J. nurs. health. 2018;8(n.esp.):e188430

\section{RESUMO}

Objetivo: caracterizar os ouvidores de vozes que participaram de um Congresso no Brasil, bem como o processo relacional com as vozes durante as suas vidas. Métodos: estudo qualitativo de abordagem descritiva, com 12 ouvidores de vozes. Os dados foram coletados em outubro de 2017. As entrevistas foram registradas na forma de anotações, organizadas e analisadas a partir de temáticas. Resultados: os participantes são em sua maioria homens, acima de 40 anos. 0 surgimento das vozes ocorreu devido a eventos traumáticos, antes dos 20 anos. 0 uso de medicamentos é a estratégia mais utilizada para o enfrentamento das vozes, enquanto escrever sobre as vozes é pouco utilizada. A maioria dos ouvidores acreditam que as vozes possam ser de entidades, bons espíritos, deuses, fantasmas e anjos. Considerações Finais: este estudo apresentou informações que potencializam a difusão do Movimento dos Ouvidores de Vozes, estimulando novas produções em diferentes cenários.

Descritores: Saúde mental; Voz; Acontecimentos que mudam a vida.

\section{ABSTRACT}

Objective: to characterize the voices listeners who participated in a Congress in Brazil, as well as the relational process with voices during their lives. Methods: this is a qualitative study of descriptive type, with the participation of 12 voice listeners. The data were collected in October 2017. The interviews were recorded in the form of annotations, organized and analyzed based on themes. Results: the participants are mostly men, over 40 years. The emergence of voices occurred due to traumatic events before the age of 20. The use of medication is the most used strategy for coping with voices, while writing about voices is a little used strategy. Most hearers believe that voices can be of entities, good spirits, gods, ghosts and angels. Conclusions: this study presented information that potentiates the diffusion of The Hearing Voices Movement, stimulating new productions in different scenarios.

Descriptors: Mental health; Voice; Life change events.

1 Enfermeira. Doutora em Enfermagem. Universidade Federal de Pelotas (UFPEL). E-mail: kantorski@uol.com.br http: / / orcid.org/0000-0001-9726-3162

2 Enfermeira. Mestre em Ciências. Instituto Federal de Educação, Ciência e Tecnologia do Rio Grande do Sul (IFRS). E-mail:roberta.machado@riogrande.ifrs.edu.br http://orcid.org/0000-0002-9087-6457

3 Enfermeira. Mestre em Ciências. Universidade Federal de Pelotas (UFPEL). E-mail: polibrina@hotmail.com http: / /orcid.org/0000-0001-6800-9536

4 Enfermeiro. Mestre em Ensino na Saúde. Universidade Federal de Santa Maria (UFSM) E-mail: enfermeiro.guipinheiro@gmail.com https: //orcid.org/0000-0003-0069-7023

5 Enfermeira. Mestre em Saúde Coletiva. Universidade Federal do Pampa (UNIPAMPA). E-mail: lurb207@gmail.com http: / /orcid.org/0000-0002-9772-5969?lang=pt 


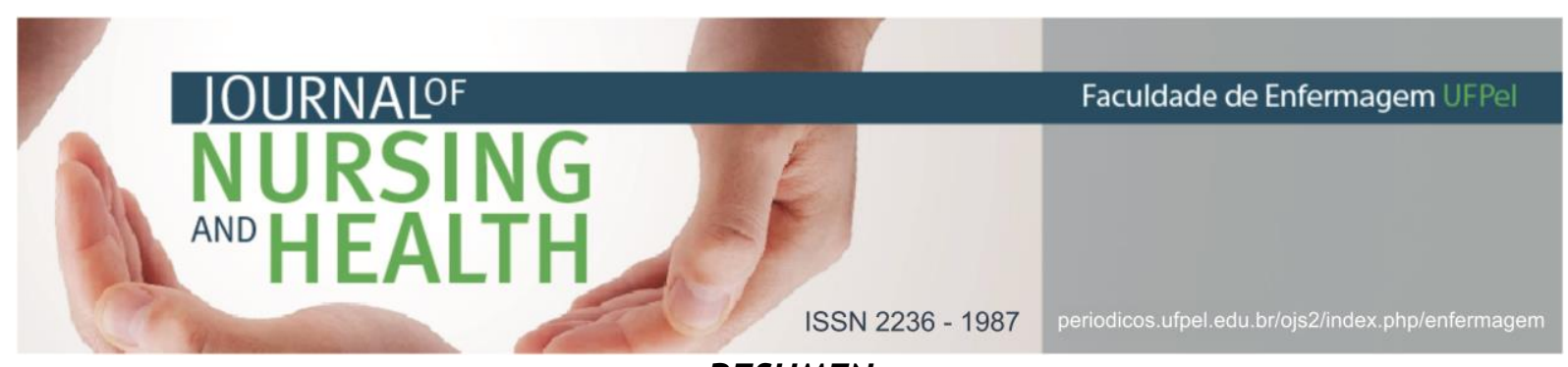

RESUMEN

Objetivo: caracterizar los oidores de voces que participaron de un Congreso en Brasil, así como el proceso relacional con las voces durante sus vidas. Métodos: estudio descriptivo y cualitativo con 12 oidores de voces. Los datos fueron colectados en octubre de 2017. Las entrevistas fueron registradas como anotaciones, organizadas y analizados a partir de temáticas. Resultados: los participantes son en su mayoría hombres, con edad superior a 40 años. El surgimiento de las voces ocurrió debido a eventos traumáticos, antes de los 20 años. El uso de medicamentos es la estrategia más utilizada para enfrentamiento de las voces, mientras que escribir sobre las voces es poco utilizado. La mayoría de los oidores creen que las voces puedan ser de entidades o buenos espíritus, dioses, fantasmas y ángeles. Consideraciones Finales: este estudio presentó informaciones que potencializan la difusión del Movimiento de los Oidores de Voces, estimulando nuevas producciones en diferentes escenarios. Descriptores: Salud mental; Voz; Acontecimientos que cambian la vida.

\section{INTRODUÇÃO}

Apesar dos esforços terapêuticos, a experiência de ouvir vozes costuma ser, na maioria das vezes, uma experiência perturbadora, que pode perdurar por um longo tempo, promovendo naquele que escuta a busca de um entendimento que the dê sentido ou a tentativa de sua eliminação. Sob uma perspectiva mais tradicional, o uso de medicação se apresenta como a primeira opção na tentativa de eliminar as vozes. ${ }^{1}$

Ao lançar mão apenas da psiquiatria tradicional, corre-se o risco de reduzir o fenômeno de ouvir vozes a um mero sintoma patológico, sem abarcar todos os sentidos que esta experiência traz para o ouvidor e dificultando que essa pessoa desenvolva estratégias eficazes para lidar com essa experiência. ${ }^{1}$

Como uma alternativa à psiquiatria tradicional vem se expandindo continuamente um movimento conhecido como Movimento de Ouvidores de vozes. Atualmente este movimento é composto por uma rede internacional que oferece uma abordagem alternativa para a compreensão da experiência do que é comumente referida como alucinações auditivas. Os três elementos principais pelos quais se guia este movimento são: $A$ organização de Grupos de ouvidores de Vozes, que oferecem apoio e ajuda de pares para os ouvintes de voz; Da utilização de técnicas inovadoras baseadas no aconselhamento focando na exeriência de ouvir vozes para serem realizadas por todos os profissionais de saúde mental envolvidos; e por último na formação de uma coalizão mais ampla de ouvidores, pesquisadores, familiares e trabalhadores engajados em diversas pesquisas acerca do tema e na garatia dos direitos dos ouvidores. ${ }^{3}$

A partir do emprego desta, nem tão nova, perspectiva, as abordagens em saúde mental dariam condições para que o sujeito ouvidor de vozes pudesse ressignificar suas experiências e percorrer um caminho que por ora se apresenta quase sempre como doloroso e alienante, decorrentes do processo de cuidar tradicional para com aqueles que ouvem vozes. ${ }^{1}$ 


\section{JOURNALOF \\ NURSING \\ ANO HEALTH}

ISSN 2236 - 198

Se por um lado, se apresenta a psiquiatria tradicional largamente utilizada nos serviços de saúde mental no Brasil e no mundo, e por outro surgem novas estratégias com caráter positivo no processo de ouvir vozes, qual caminho deve-se recorrer para o aprimoramento das técnicas de cuidado as pessoas que ouvem vozes?

Nos serviços de saúde mental a compreensão de cuidado encontra-se entrelaçada com a lógica da doença e cotidianamente está associada a incorporação do medicamento como recurso para seu enfrentamento. Mas, é necessário desenvolver alternativas mais comprometidas com a percepção dos usuários, direcionadas pelo exercício de autonomia e empoderamento dos mesmos. ${ }^{2}$

Ainda que este tema já tenha sido objeto de estudo e publicações desde a década de 1980 em âmbito internacional, os estudos no campo da saúde relacionados à escuta de vozes no Brasil ainda são escassos, e mesmo os encontrados, muitos deles apresentam a escuta de vozes relacionada à sintomatologia da esquizofrenia.

Apesar da singularidade de cada caso, conhecer o perfil e as percepções de cada ouvidor contribui para um melhor entendimento deste processo, bem como para aqueles que necessitam de um maior aprofundamento sobre as estratégias desenvolvidas e aqui compartilhadas.

Desta forma, o objetivo deste estudo foi 0 de caracterizar os ouvidores de vozes que participaram de um Congresso no Brasil, bem como
- processo relacional com as vozes durante as suas vidas.

\section{METODOLOGIA}

Este artigo trata de um estudo de abordagem descritiva sobre os ouvidores de vozes e análise qualitativa acerca da primeira experiência da escuta das vozes, das emoções e sentimentos mediante o seu aparecimento e as estratégias adotadas para o enfrentamento da experiência. Os resultados discutidos integram a pesquisa: "Ouvidores de vozes - novas abordagens em saúde mental" aprovado pelo Comitê de Ética da Faculdade de Medicina da Universidade Federal de Pelotas sob o parecer 2.201.138 de 3 de agosto de 2017. Foram cumpridos todos os procedimentos éticos previstos na legislação vigente.

Os dados consistem em 12 entrevistas feitas com Ouvidores de Vozes que participaram do I Congresso de Ouvidores de Vozes no Brasil, realizado em 20 e 21 de outubro de 2017 no Rio de Janeiro - RJ.

Os dados foram coletados em outubro de 2017. As entrevistas foram registradas na forma de anotações, organizadas e analisadas a partir de temáticas.

\section{RESULTADOS E DISCUSSÃO}

Para uma melhor visualização, são apresentadas as principais características demográficas e socioeconômicas dos 12 entrevistados. A maioria, oito, autorreferiram ser do sexo masculino, com idades entre 31 a 60 anos, sete com cor de pele branca e 
sete solteiros. Sete referiram residir na cidade do Rio de Janeiro. Em relação à escolaridade, quatro apresentavam Graduação e Pós-Graduação completa. Em relação à renda, apenas um entrevistado apresentou emprego formal com carteira assinada (Tabela $1)$.

De acordo com os dados deste estudo, metade dos entrevistados afirmou ouvir vozes desde a infância até os vinte anos de idade (Tabela 2 ). Um estudo publicado em 2011, que acompanhou 337 crianças de 7 e 8 anos por cinco anos que ouviam vozes, os resultados evidenciaram que a maioria (76\%) das crianças deixou de ouvir vozes aos 12 e 13 anos, evidenciando assim que a maioria das experiências auditivas são transitórias e desaparecem com o tempo. ${ }^{4}$

Outro dado importante relacionado à audição de vozes durante a infância foi que o fato de ouvir mais de uma voz e a atribuição dessas a uma fonte externa, como espíritos ou fantasmas, foram os mais fortes preditores de ouvir vozes após os cinco anos de acompanhamento.

Os resultados deste estudo também apontaram que apenas cinco entrevistados conversaram com alguém sobre as vozes na primeira vez que as escutaram. Apesar dos dados não afirmarem que essas pessoas que conversaram com alguém sobre a primeira vez que ouviu alguma voz fossem criança, vale a pena ressaltar a importância do reconhecimento parental acerca da escuta das vozes.

No caso de crianças que apresentam queixas somáticas, problemas comportamentais,
ISSN 2236 - 1987

resultados escolares mais baixos ou problemas de pensamento, a possibilidade da escuta de vozes também deve ser considerada. Por outro lado, quando uma criança revela a existência da escuta de vozes sem complicações, a escuta das vozes geralmente se apresenta de forma transitória. ${ }^{4}$

Tabela 1: Principais características demográficas dos participantes.

\begin{tabular}{|c|c|}
\hline Características & $\mathbf{N}$ \\
\hline \multicolumn{2}{|l|}{ Idade } \\
\hline $31-40$ & 2 \\
\hline $41-50$ & 4 \\
\hline $51-60$ & 6 \\
\hline \multicolumn{2}{|l|}{ Cor } \\
\hline Branca & 8 \\
\hline Parda & 3 \\
\hline Negra & 1 \\
\hline \multicolumn{2}{|l|}{ Sexo } \\
\hline Masculino & 8 \\
\hline Feminino & 4 \\
\hline \multicolumn{2}{|l|}{ Estado civil } \\
\hline Solteiro & 7 \\
\hline Casado ou com companheiro & 3 \\
\hline Separado & 1 \\
\hline Viúvo & 1 \\
\hline \multicolumn{2}{|l|}{ Cidade onde mora } \\
\hline Rio de Janeiro & 7 \\
\hline Campinas & 2 \\
\hline Porto Alegre & 1 \\
\hline Brasília & 1 \\
\hline Campo Grande & 1 \\
\hline \multicolumn{2}{|l|}{ Escolaridade } \\
\hline Ensino Fundamental Incompleto & 1 \\
\hline Ensino Fundamental Completo & 1 \\
\hline Ensino Médio Completo & 5 \\
\hline Ensino Superior Completo & 3 \\
\hline Pós-Graduação Completa & 1 \\
\hline Não respondeu & 1 \\
\hline \multicolumn{2}{|l|}{ Fonte de renda } \\
\hline Emprego formal com carteira & 1 \\
\hline assinada & 6 \\
\hline Aposentadoria & 1 \\
\hline Renda Familiar & 2 \\
\hline Pensionista & 2 \\
\hline LOAS* & \\
\hline Total & 12 \\
\hline
\end{tabular}




\section{JOURNALOF \\ NURSING \\ AND HEALTH}

ISSN 2236 - 1987

muitas ocasiões levam pessoas que ouvem vozes ao isolamento. 0 estigma também se apresenta arrolado como causa do não compartilhamento desta experiência, principalmente pelo estigma social relacionado à rotulação dessas pessoas à "doentes mentais". 7

Tabela 2: Características referentes à primeira vez que ouviu vozes.

\begin{tabular}{lc}
\hline Características & N \\
\hline Idade que ouviu pela primeira & \\
vez & 2 \\
Desde criança & 4 \\
$11-20$ & 4 \\
21 aos 30 & 1 \\
31 aos 40 & 1 \\
$\quad$ Ignorado & \\
Conversou com alguém sobre & \\
as vozes na primeira vez & 5 \\
$\quad$ Sim & 6 \\
$\quad$ Não & 1 \\
$\quad$ Ignorado & \\
Com quem conversou pela & \\
primeira vez que escutou as & \\
vozes & \\
$\quad$ Psiquiatra & 1 \\
Profissional da saúde & 1 \\
Namorada & 1 \\
Não conversou & 6 \\
Não informou & 1 \\
Ignorado & 2 \\
Total & 12 \\
\hline
\end{tabular}

Por este caminho, é incontestável a presença de estigmas e preconceitos arraigados na sociedade imbuída pelo discurso biomédico, o que dificulta de inúmeras maneiras a conquista de espaços na sociedade. A difusão do discurso biomédico, que define a experiência de ouvir vozes como um sintoma psicopatológico de doença mental, apresenta grande influência na sociedade contemporânea, culminando num processo de estigmatização e exclusão de pessoas que ouvem vozes de forma geral. ${ }^{8} \mathrm{E}$, no que concerne às questões do trabalho, este estudo evidenciou que, mesmo 
com a maior parte dos entrevistados estarem em idade laboral, apenas um afirmou ter um regime formal de trabalho.

\section{Emoções, Sentimentos e Estratégias associadas ao aparecimento das vozes}

É possível conviver com as vozes? Sim, é a resposta que a maioria dos ouvidores de vozes dizem ao serem questionados sobre a possibilidade de conviver com as vozes que escutam. No entanto, o processo para se estabelecer uma convivência saudável não é simples e nem fácil.

Ao ouvir a ou as vozes pela primeira vez, o medo é a emoção mais comum de ser vivenciada. Um estudo realizado por Cristina Contini, que questionou 150 pessoas que ouvem vozes sobre o que elas sentiram pela primeira vez ao ouvi-las, o medo foi a emoção mais citada, em especial se a origem das vozes deriva de um evento traumático. ${ }^{9}$

Entre os ouvidores de vozes dessa pesquisa, o cansaço, a sobrecarga, andar de ônibus e ficar sozinho foram relatados como situações que acionam as vozes. O surgimento delas parece ainda estar relacionado com as demandas emergentes com a vida adulta, na qual o trabalho e o estudo destacam-se como gatilhos da experiência de ouvir vozes.

Estava indo trabalhar e ouvi uma voz feminina [...] vou te ajudar, fica calmo, vai lá! (Ouvidor 2)

Vivia o momento errado, ter estudado com a televisão e eu falava com ela, os números. (Ouvidor 5)

No trabalho de repente escuto que chamaram feia, incapaz. (Ouvidora 6)

Eu havia acabado estudar de sexta-feira para sábado às 02h30min. estava passando por uma situação de pressão no trabalho, com meu chefe, e com sobrecarga de estudo. Passava o dia trabalhando e depois chegava do trabalho e ia para a faculdade, ao chegar em casa, estudava até às 2h30min. (Ouvidor 12)

Com relação às emoções e sentimentos relacionados ao surgimento das vozes foram citadas: o medo, raiva, depressão, tristeza e insegurança, identificadas como gatilhos para ocorrência das vozes. 0 que leva a maioria desses ouvidores relatar que elas prejudicam suas atividades diárias, deixando-os aborrecidos.

Situações estressantes $e$
perturbadoras como brigas $e$
financeira. (Ouvidor 8)

Rejeição, pânico, síndrome do pânico. (Ouvidor 1)

Contudo, essas emoções quando bem direcionadas contribuem para a sobrevivência do ser humano, impulsionando-o para se proteger de situações diversas do dia a dia. Neste sentindo, é importante estar atento ao que a ou as vozes estão comunicando, pois o que gera o medo não são as vozes, mas sim o que elas dizem, independente delas serem positivas, negativas ou neutras. ${ }^{9}$ 


\section{JOURNALOF \\ NURSING \\ ANO HEALTH}

Além disso, o medo também está relacionado com a associação que existe entre ouvir vozes e à loucura, principalmente a esquizofrenia, levando os ouvidores a vivenciarem essa experiência de forma solitária, para evitar ser estigmatizado. Dessa forma a experiência passa a se tornar assustadora, por isso o medo é a emoção mais presente no início do processo de ouvir vozes.

O surgimento das vozes entre os ouvidores desse estudo estava relacionado as perdas, tais como: falecimento de um amigo próximo da família, desemprego/demissão/sentirse desnecessário, apaixonou-se e foi rejeitado e grande tensão em casa ou no relacionamento. Por outro lado, as experiências de vida menos citadas relacionada à escuta das vozes foram: morar sozinho pela primeira vez, menarca/gravidez/aborto, ter assistido alguma sessão, ritual satânico ou evento espiritual, presenciou suicídio ou contemplou/tentou suicidar-se, a saída de um filho de casa/ ou quando o último filho saiu de casa e ter iniciado um curso acadêmico. Esse resultado corrobora com outros estudos que trazem a relação do aparecimento das vozes com uma vivência traumática vivenciada pelo(a) ouvidor(a), sendo os traumas muito singulares entre os/as ouvidores(as), pois se relacionam com as características socioculturais e históricas de cada um e cada uma. 6, 910

Em outro estudo, o aparecimento das vozes foi relacionado pelos entrevistados a uma série de vulnerabilidades sociais e emocionais, sendo os mais comuns os problemas de
ISSN 2236 - 1987

autoestima, raiva, vergonha e culpa, que por sua vez estavam ligados a experiências adversas ocorridas no passado. Desta forma, os participantes forneceram informações relevantes e suficientes para inferir uma relação entre as vozes e as suas histórias de vida. ${ }^{5}$

O movimento dos ouvidores de vozes, diferentemente da psiquiatria tradicional, oferece uma abordagem diferente em relação a audição das vozes, enquanto a segunda visa a erradicação e supressão das vozes, a primeira valoriza a audição como algo significativo, singular de acordo com o contexto da história de vida de cada ouvidor(a), promovendo uma procura por caminhos positivos para se comunicar com elas. ${ }^{1}$

Em um estudo com grupos de ouvidores de vozes na Itália, os participantes perceberam que a existência das vozes estava relacionada com as experiências de vida e com os pensamentos de cada ouvidor(a), devendo os ouvidores(as) estabelecer um diálogo com as vozes, com a finalidade de buscar informações sobre elas, procurando saber o que elas querem realmente comunicar. Essa abordagem permite que $0 / a$ ouvidor(a) perceba que 0 problema não são as vozes, mas as possíveis emoções e sentimentos que conviver com elas causam. ${ }^{9}$

De acordo com os participantes deste estudo, metade deles consegue dialogar com as vozes, sendo capazes de influenciá-las, inclusive de recusar ordens dadas pelas vozes de comando. Também, mostram reconhecer a relação entre seus pensamos e o teor das vozes. 


\section{ISSN 2236 - 1987}

Quando não aguento mais, obedeço! (Ouvidor 2)

Um pouco mais controlada com o tratamento, aqui tem profissionais para nos ouvir. (Ouvidora 4)

Depende do que for, cumpro! (Ouvidora 6)

Não me consomem, convivo bem atualmente [...] quando não me é prejudicial e nem ao outro eu sigo. (Ouvidora 7)

Podem ser positivas ou negativas, depende do meu pensamento. (Ouvidor 8)

As estratégias cognitivas de enfrentamento das vozes relatadas foram: ouvir seletivamente a voz, pensar em outra coisa e tentar limitar o contato com as vozes; seguida de estratégias de mandar a voz embora; concentra-se em escutá-la e apenas uma minoria utiliza a estratégia de fazer algum trato com as vozes.

Conversarmos. (Ouvidor 2)

Ajudam, acolhem, ouvem, escutam. (Ouvidora 4)

Medicaram, foi péssimo! (Ouvidora 7)

Grupo de ouvidores. (Ouvidor 11)

Ocupar a mente. (Ouvidor 10)

A estratégia comportamental de enfrentamento das vozes menos citada pelos participantes foi a escrita de um diário sobre as vozes, no entanto os experts orientam a construção de um diário como uma alternativa positiva para compreender as vozes. Contudo vivemos em um país onde $8,3 \%$ da população com 15 anos ou mais é analfabeta, ${ }^{11}$ o que dificulta 0 uso dessa estratégia para os ouvidores que não sabem ler e nem escrever.

Porém, uma outra alternativa viável e muito eficiente são os grupos de ouvidores de vozes, que surgem como um espaço coletivo de compartilhamento de experiências, auxiliando os e as ouvidores(as) a conviverem positivamente com as vozes, por meio do compartilhamento de vivências, experiências e divulgando outras estratégias de enfrentamento, sem que os participantes se sintam estigmatizados.

As estratégias comportamentais como tentar escapar das vozes, se distrair e começar a fazer algo, também foram citadas pelos ouvidores desse estudo, porém como já mencionamos anteriormente evitar as vozes, geram mais angústia e medo. ${ }^{12-}$ 13

Metade dos participantes relataram como estratégia para evitar as vozes a medicalização. Mas, o uso de psicoterápicos não significa que as vozes irão desaparecer, pois mesmo fazendo uso deles em muitas situações a presença das vozes se mantém no cotidiano dos (as) ouvidores (as).

Em relação ao tratamento, as psicoterapias que trabalham com a proposta de formular e revisar as crenças inúteis sobre os eventos emocionais que sustentam as vozes podem ser benéficas na melhoria da valência afetiva da voz, reduzindo o sofrimento. ${ }^{6}$ 


\section{IOURNALOF

\section{A representação das vozes}

Assim como desenvolver estratégias para identificar as emoções e sentimentos gerados pela escuta das vozes, conhecer a representação das vozes também auxilia na convivência com elas, já que o seu aparecimento, em sua grande maioria, está relacionado a um acontecimento traumático, sendo as vozes a expressão daquilo que aconteceu na vida do(a) ouvidor(a). Neste sentido, conhecer e compreender o significado das vozes colabora no processo de aprendizagem de lidar com as emoções que as vozes causam, sendo um instrumento relevante no processo de recuperação dos(as) ouvidores(as).

Para conhecer a representação das vozes é preciso explorar a relação que existe entre o ouvir vozes e a história de vida do(a) ouvidor(a), buscando alternativas para resolver seus problemas emocionais, entre outros. Dessa forma, a ênfase é estimular o/a ouvinte a compreender o que as vozes realmente querem comunicar, para que seja possível encontrar uma solução para as prováveis dificuldades que elas causam no cotidiano do(a) ouvidor(a).

Três perguntas são pertinentes para conhecer a representação das vozes. Quem são as pessoas que as vozes representam? Quais os problemas que as vozes representam? Quais são as características das vozes? Essas questões colaboram para a identificação das pessoas envolvidas no evento traumático e/ou estressor e quais problemas elas representam. ${ }^{12}$

\begin{tabular}{ccc} 
Neste & \multicolumn{2}{c}{ estudo, os(as) } \\
ouvidores(as) na sua maioria
\end{tabular}

identificaram as vozes com conteúdo negativo, sendo de pessoas que não conhecem, mas que são de uma pessoa viva e que faz parte da sua rotina diária.

Um estudo realizado na Europa Ocidental (Dinamarca, Holanda, Reino Unido, Suécia), Austrália e Camarões, demonstra que as representações comuns incluíam pais abusivos, amigos ou conhecidos, ou um abusador do sexo masculino que havia vitimado o ouvinte de alguma forma. Assim, apresentou maior frequência de representações de vozes masculinas. ${ }^{5}$

Outro estudo com 34 ouvidores, realizado na Austrália, apresentou opiniões sobre as vozes ouvidas, tanto no que diz respeito ao conteúdo negativo da(s) voz(es), quanto ao que elas (as vozes) representam para os sujeitos. Sendo que o estudo apresentou uma proporção estimada de conteúdos negativos da(s) voz(es) de $7 \%$ a $25 \% .{ }^{14}$

Já o estudo realizado na Espanha, sugere que a relação entre as vozes e o afeto negativo sobre as vozes é colocado em uma relação não direta, mas mediada pelas crenças de malevolência e onipotência sobre as vozes, indicando com o uso de escalas, que as crenças sobre intenções malévolas das vozes mediam a relação com ansiedade e depressão em indivíduos ouvidores de vozes. Estabelece ainda, que o sofrimento de um ouvidor de vozes pode ser considerado a partir de suas crenças sobre as vozes e a sua forma de enfrentamento. Ou seja, para que o indivíduo se sinta angustiado com a condição de ouvir vozes, é necessário que ocorra uma valorização negativa 
desta experiência. Caso isso não ocorra, é possível que o ouvidor não se sinta mal com sua condição, desenvolvendo assim, um enfrentamento positivo sobre a voz escutada. ${ }^{15}$

Em relação às crenças, este estudo apresenta a visão dos ouvidores que em sua maioria acreditam que as vozes possam ser de entidades, bons espíritos, deuses, fantasmas e anjos.

Sou Deus, sou o diabo! (Ouvidor 1)

Anjo da guarda. (Ouvidor 2)

Nesse sentido, várias das crenças sobre as vozes foram correlacionadas com o número de anos que a pessoa tinha ouvido vozes: onipotência; malevolência; crenças metafísicas negativas; e crenças positivas. Apresentando uma ligação entre o tempo de escuta de vozes e a associação que o sujeito desenvolve como representação da voz em seu cotidiano. Por outro lado, visões positivas de vozes têm sido frequentemente consideradas mais adaptativas porque elas são apontadas por ouvintes de voz não psiquiátricos, ou seja, aqueles indivíduos que não foram captados pelo sistema psiquiátrico tradicional. ${ }^{14}$ Dessa forma, são necessários desenvolvimentos de esquemas que apoiem os ouvidores de vozes, sendo uma alternativa de intervenção.

Além dos métodos tradicionais de reestruturação cognitiva, estão surgindo métodos de trabalho com vozes que adotam uma abordagem mais experiencial, que pode ser adequada para intervir em um nível esquemático, com o desenvolvimento de esquemas apoiadores. ${ }^{14}$

Para a psiquiatria tradicional, ouvir vozes está relacionado a um sintoma principal da esquizofrenia, no entanto, o movimento de ouvidores de vozes compreende as vozes como um evento natural das experiências de vida dos sujeitos. Logo, esse movimento orienta os(as) ouvidores(as) a valorizar as vozes positivas, e em relação às vozes negativas a orientação é tentar compreende-las e controlá-las de modo a manter ou recuperar o controle de sua própria vida. ${ }^{16}$ Assim, reconhecer se o significado das vozes expressam o que o(a) ouvidor(a) está sentindo ou pensando naquele momento. ${ }^{12}$

Com isso, os Ouvidores presentes neste I Congresso brasileiro de Ouvidores de Vozes têm em comum o desejo de aprender a conviver de forma mais harmoniosa com as vozes e a sociedade. $\mathrm{E}$ suas expectativas constroem-se em torno da possibilidade de:

Lidar com as vozes. Não é fácil, não tem cura. (Ouvidor 3 )

Aprender, ter empoderamento para cuidar, e ser meu próprio cuidador, com o tratamento da medicação, em união com a equipe do hospital dia, com as oficinas terapeutas oferecidas, vivendo hoje e sonhar o amanhã. (Ouvidor 4)

Atender melhor o manuseio com as vozes. (Ouvidor 7 ) 


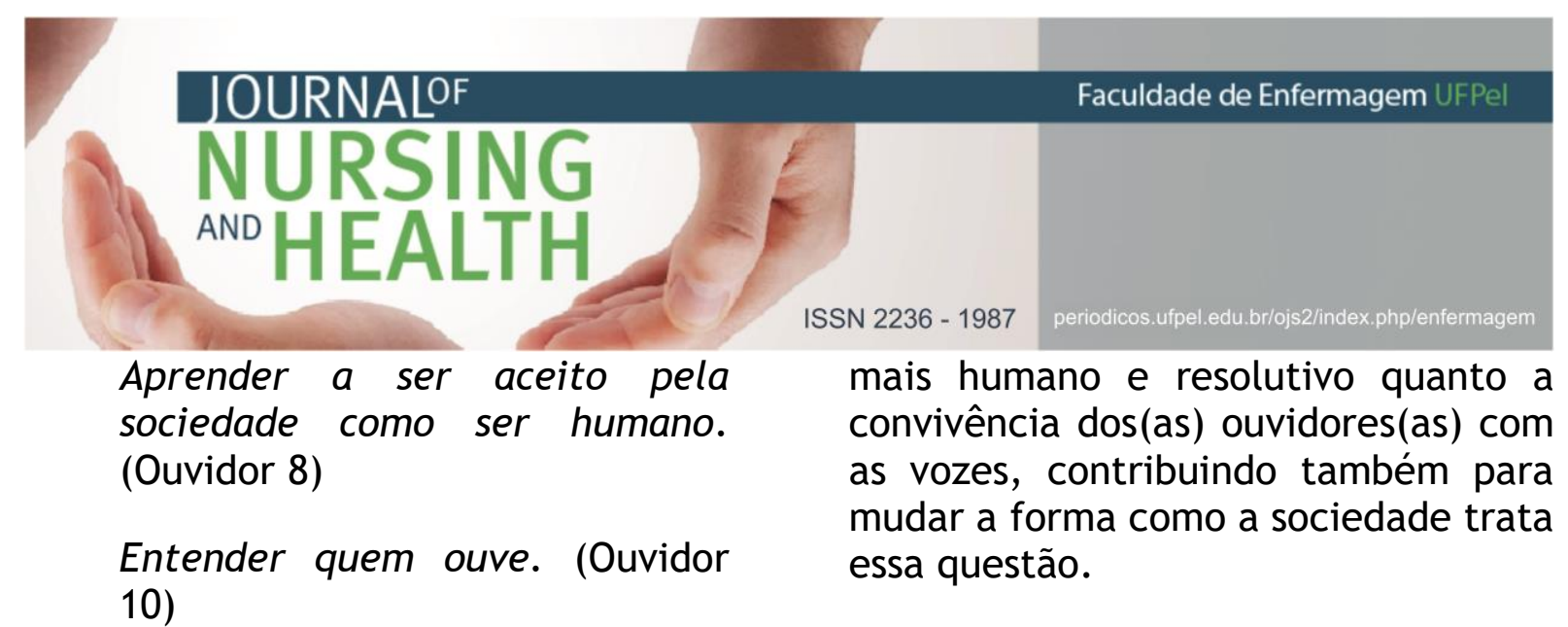

\section{REFERÊNCIAS}

Como lidar com as vozes. (Ouvidor 11)

\section{CONSIDERAÇÕES FINAIS}

Este estudo é um recorte de um trabalho maior e que não deve ser generalizado, porém, as informações por ele fornecidas apresentam um potencial para promover a difusão do Movimento dos Ouvidores de Vozes, além de estimular a produção de novos estudos com maior profundidade, considerando outras localidades e culturas.

De modo geral, o estudo traz as características sociodemográficas dos participantes, as características da primeira vez que ouviram as vozes, emoções e os sentimentos originados pela escuta das vozes, bem como as representações que essas vozes possuem para quem as escuta. Além disso, mostra algumas estratégias de enfrentamento utilizadas pelos(as) ouvidores(as).

As informações apontam que o medo é a emoção mais relatada pelos ouvidores de vozes, e que essa emoção está ligada a representação que esta voz traz, em especial quando ligadas a um evento traumático na história de vida desses sujeitos.

Dessa forma, conhecer as características dos(as) ouvidores e a relação que eles(as) têm com as vozes, possibilita construir modos de cuidado

1 Barros OC, Serpa Jr OD. Ouvir vozes: um estudo netnográfico de ambientes virtuais para ajuda mútua. Physis. [Internet]. 2017 dez[acesso em 2018 ago 10];27(4):867-88. Disponível em: http://www.scielo.br/scielo.php?scrip $\mathrm{t}=\mathrm{sci}$ arttext\&pid=S0103-

73312017000400867\&lng=pt.

2 Onocko-Campos RT, Passos E, Palombini AL, Santos DVD, Stefanello $S$, Gonçalves LLM, et al. A Gestão autônoma da medicação: uma intervenção analisadora de serviços em saúde mental. Ciênc saúde coletiva [Internet]. 2013 out[acesso em 2018 ago 10];18(10):2889-98. Disponível em: http://www.scielo.br/scielo.php?scrip $\mathrm{t}=\mathrm{sci}$ arttext\&pid=S1413-

$81232013001000013 \&$ ing $=e n$.

3 Jones N, Marino CK, Hansen MC. The Hearing Voices Movement in the United States: findings from a national survey of group facilitators. Psychosis [Internet]. 2015 Nov[cited 2018 Aug 10];8(2):106-17. Avalaible from: https://www.tandfonline.com/doi/ful l/10.1080/17522439.2015.1105282?scr oll=top\&needAccess=true

4 Bartels-Velthuis AA, Willige $G$, Jenner JA, Os J, Wiersma D. Course of auditory vocal hallucinations in childhood: 5-year follow-up study. Bj psych [Internet]. 2011 Out[cited 2018 Aug 10];199(4):296-302. Avalaible from:

https://www.cambridge.org/core/ser 
vices/aop-cambridge-

core/content/view/6DFFC222964BFDE 6F70E7EFCB7B8794F/S0007125000258 327a.pdf/course_of_auditory_vocal_h allucinations_in_childhood_5year_foll owup_study.pdf

5 Corstens $D$, Longden $E$. The origins of voices: links between life history and voice hearing in a survey of 100 cases. Psychosis [Internet]. 2013 Sept[cited 2018 Aug 10];5(3):270-85. Avalaible from:

https: / /www.tandfonline.com/doi/ful l/10.1080/17522439.2013.816337?scro ll=top\&needAccess=true

6 McCarthy-Jones S, Longden E. Auditory verbal hallucinations in schizophrenia and post-traumatic stress disorder: common phenomenology, common cause, common interventions? Front psychol [Internet]. 2015 July[cited 2018 Aug 10];6(n.esp.):1-12. Available from: https: / /www.frontiersin.org/articles/ 10.3389/fpsyg.2015.01071/full

7 Barbero MÁM, Pereira MCC, Villalba GP, Hernández MVM. Escuchando la voz de las personas que escuchan voces. Rev asoc esp neuropsiquiatr [Internet]. 2017[acceso 2018 ago 10];37(131):39$61 . \quad$ Disponible: http: / / www.revistaaen.es/index.php/ aen/article/view/16989/16859

8 Corradi-Webster CM, Santos MV, Leão EA. Construindo novos sentidos e posicionamentos em saúde mental: grupo de ouvidores de vozes. In: Rasera EF, Taverniers K, Vilches-Álvarez 0 . Construccionismo social en acción: prácticas inspiradoras en diferentes contextos. Ohaio: Taos Institute Publications; 2017:167-93.
9 Kantorski LP, Antonacci MH, Andrade APM, Cardano M, Minelli M. Grupos de ouvidores de vozes: estratégias e enfrentamentos. Saúde debate [Internet]. 2017 out/dez[acesso em 2018 ago 10];41(115):1143-55. Disponível em: http://www.scielo.br/scielo.php?scrip $\mathrm{t}=\mathrm{sci}$ _arttext\&pid=S0103-

11042017000401143

10 Smith DB. Você pode viver com as vozes em sua cabeça? Rev latinoam psicopatol fund [Internet]. 2007 jun[acesso em 2018 ago 10];10(2):295306. Disponível em: http://www.scielo.br/pdf/rlpf/v10n2 /1415-4714-rlpf-10-2-0295.pdf

11 IBGE. Pesquisa Nacional por Amostra de Domicílios: síntese de indicadores 2014. Rio de Janeiro [Internet]: IBGE, Coordenação de Trabalho e Rendimento; 2015 [acesso em 2018 ago 10]. Disponível em: https://biblioteca.ibge.gov.br/visuali zacao/livros/liv94935.pdf

12 Baker PK. The Voice inside: a practical guide to coping with hearing voices. Manchester, UK: Mind Publications; 1996.

13 Contini, C. Sentire le voce: manuale di affrontamento. Vignola: Self Publishing; 2013.

14 Thomas N, Farhall J, Shawyer F. Beliefs about voices and schemas about self and others in psychosis. Behav cogn psychother [Internet]. 2015 Oct[cited 2018 Aug 10];43(2):209-23. Available from: https://www.cambridge.org/core/jou rnals/behavioural-and-cognitivepsychotherapy/article/beliefs-aboutvoices-and-schemas-about-self-andothers-in- 
psychosis/9406007D15071445A954C38

\section{ED4C6}

15 León-Palacios MG, Úbeda-Gómez J, Escudero-Pérez $S$, Barros-Albarán MD, López-Jiménez AM, Perona-Garcelán S. Auditory Verbal Hallucinations: can beliefs about voices mediate the relationship patients establish with them and negative affect? Span j psychol [Internet]. 2015 Jan [cited 2018 sept 11];18: e76. Available form: https://www.cambridge.org/core/jou rnals/spanish-journal-of-

psychology/article/auditory-verbalhallucinations-can-beliefs-aboutvoices-mediate-the-relationshippatients-establish-with-them-andnegative-

affect/421233E896022A2755AD22B7C0 7FEBB6

16 Romme M, Escher S. Na companhia das vozes: para uma análise da experiência de ouvir vozes. Lisboa:

Estampa; 1997.

Data de publicação: 19/09/2018 